\title{
Concept of aeroponic biomass cultivation and biological wastewater treatment system in extraterrestrial human base
}

\author{
Anna Jurga ${ }^{1, *}$, and Joanna Kuźma ${ }^{2}$ \\ ${ }^{1}$ Wroclaw University of Science and Technology, Faculty of Environmental Engineering, \\ Wyb. Wyspianskiego 27, 50-370 Wroclaw, Poland \\ ${ }^{2}$ Wroclaw University of Science and Technology, Faculty of Mechanical and Power \\ Engineering, Wyb. Wyspianskiego 27, 50-370 Wroclaw, Poland
}

\begin{abstract}
The article presents a concept of a biomass cultivation and a wastewater treatment system in future Planetary Base (PB) e.g. Moon or Mars, designed for eight-person crew. These two subsystems are part of Life Support System (LSS), which aims at providing proper environmental condition for human habitation.
\end{abstract}

\section{Introduction}

Extraterrestrial human habitation is now a matter of time. In deep space missions the most crucial issue is development of a regenerative life support system (RLSS), which will provide appropriate environmental conditions for human habitation. Example of RLSS is presented in Figure 1. Such system is divided into few subsystems:

- $\quad$ water subsystem - responsible for water recovery and purification, also nutrient recovery,

- biomass subsystem - in charge of food production and ensuring the required goods,

- atmosphere subsystem - responsible for air purification and maintaining the proper pressure, temperature, humidity and air composition in the cabins,

- $\quad$ solid waste subsystem - provides solid waste management (e.g. feces, inedible biomass) and possible nutrient recovery.

The biomass and the water subsystems are the most crucial parts of RLSS. Water and food are ones of the most consumed products in space missions [1], thus its constant delivery to the future PB will be impossible and inadequate. It is well shown by present delivery cost of one pound of water to the International Space Station (ISS) stationed ca. $400 \mathrm{~km}$ from Earth, ranging to nearly $10.000 \$$ [2]. The need to design proper recovery and purification of water in-situ seems to be evident, especially for human base located much further than Low Earth Orbit (LEO). The costs are similar in terms of food delivery. Thus, it can be concluded, that in future extraterrestrial colony these particular systems should be designed in closedloop setup. This paper focus on the biomass and water subsystem design.

\footnotetext{
* Corresponding author: anna.jurga@pwr.edu.pl
} 


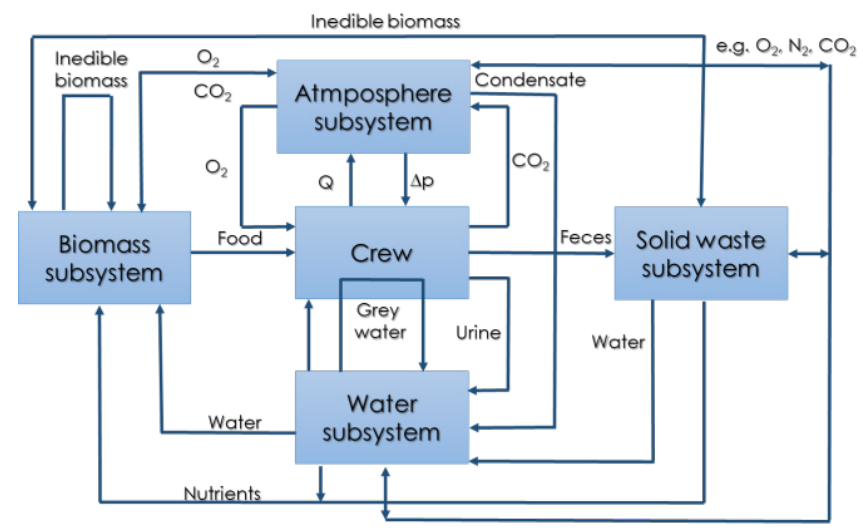

Fig. 1. Regenerative Life Support System scheme.

\section{General description of the system}

Future RLSS considered in this paper is presented schematically in Figure 2. It does not include any element of the solid waste and atmosphere subsystem, but it shows e.g. sources of Carbon Dioxide and Oxygen. Main assumption in this project is to create regenerative biomass and water subsystem. Subsystem should be connected and assure water and nutrient recovery. In this concept biomass cultivation module provides fresh food for crew, oxygen production and carbon dioxide. Main components of biomass system are plants, insects and cyanobacteria. Each of them provides specific elements required in astronaut's diet $[3,4]$ Plants are source of vitamins, minerals and calories [3]. Insects, more precisely Dubia cockroaches provides calories and proteins, and in the last algae supplies macro and microelements. Plants are cultivated in soilless method, by keeping crops in the air and by sprinkle their roots with nutrient solution. Required water and nutrient for plants is recovered from wastewater generated in the colony. Water recovered from cultivation is purified and sterilized and can be used as potable water by crew, insects and cyanobacteria.

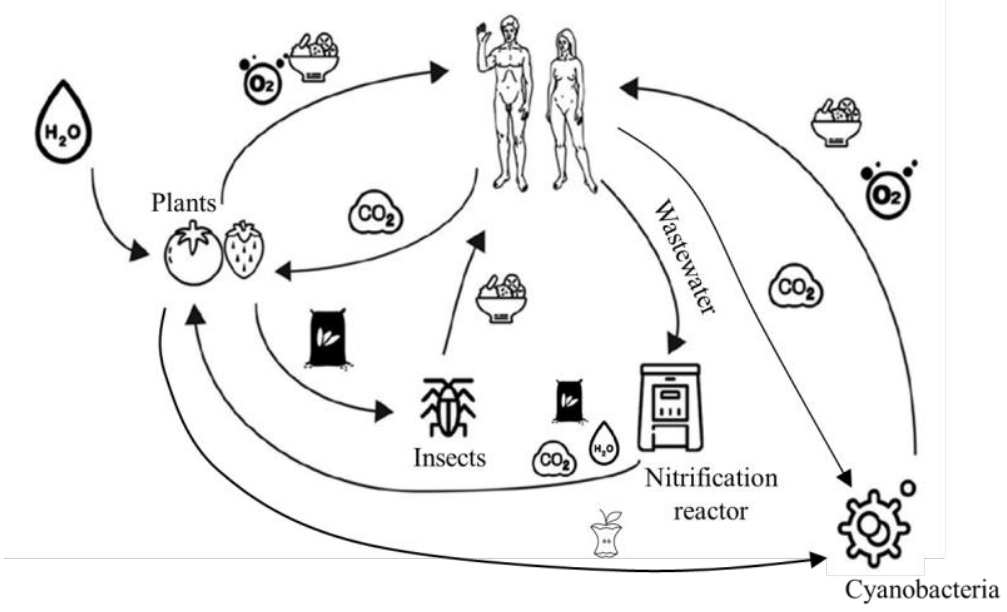

Fig. 2. Part of RLSS in extraterrestrial human base scheme. 


\section{Biomass subsystem}

\subsection{Diet content selection}

Diet is calculated for 6-8 average crewmembers, which is defined by Anderson et al. [4] as the crewmember mass range from a 95th percentile American male, with a total body mass of $99 \mathrm{~kg}$, to a $5^{\text {th }}$ percentile Japanese female, with a total mass of $53.0 \mathrm{~kg}$ for whom daily calorie consumption is $12.72 \mathrm{MJ} \cdot$ crewmember $^{-1} \cdot$ day $^{-1}$. Diet content is determined by taking into account following factors: plant calorific value, plant growth period, plants variety, the mass that one man can eat and feasibility to grow in aeroponic system. This approach allowed to select: Snap Bean, Soybean, Strawberry, Tomato, Wheat and White Potato. Period of growth of Wheat and White potato differs from the remaining crops, which allows to reduce required surface. Detailed data of cultivation surface dimensions are shown in the table 1. Plants provides daily ca. $2200 \mathrm{kcal} \cdot$ crewmember $^{-1} \cdot$ day $^{-1}$.

Table 1. Crops cultivation design parameters.

\begin{tabular}{|c|c|c|c|c|c|c|c|c|}
\hline \multicolumn{2}{|c|}{ Crop } & $\begin{array}{c}\text { Snap } \\
\text { Bean }\end{array}$ & Soybean & Strawberry & Tomato & Wheat & $\begin{array}{c}\text { White } \\
\text { Potato }\end{array}$ & Total \\
\hline Growing area & $\mathrm{m}^{2}$ & 23.0 & 30.0 & 15.0 & 22.0 & 100.0 & 45.0 & 235.0 \\
\hline $\begin{array}{c}\text { Edible } \\
\text { biomass }\end{array}$ & $\mathrm{g} \cdot \mathrm{d}^{-1}$ & 3415.5 & 151.2 & 1168.2 & 3822.7 & 2273.0 & 4738.5 & 15569.1 \\
\hline $\begin{array}{c}\text { Inedible } \\
\text { biomass }\end{array}$ & $\mathrm{g} \cdot \mathrm{d}^{-1}$ & 4098.6 & 2041.2 & 2166.9 & 2803.5 & 30000.0 & 4061.3 & 45171.4 \\
\hline $\begin{array}{c}\text { Oxygen } \\
\text { production }\end{array}$ & $\mathrm{g} \cdot \mathrm{d}^{-1}$ & 418.9 & 417.3 & 379.8 & 579.9 & 5600.0 & 1450.4 & 8846.3 \\
\hline $\begin{array}{c}\text { Carbon } \\
\text { dioxide } \\
\text { uptake }\end{array}$ & $\mathrm{g} \cdot \mathrm{d}^{-1}$ & 1152.1 & 573.9 & 522.3 & 797.3 & 7700.0 & 2035.4 & 12780.9 \\
\hline \begin{tabular}{c} 
Water uptake \\
\hline $\begin{array}{c}\text { Metabolic } \\
\text { energy }\end{array}$
\end{tabular} & $\mathrm{kg} \cdot \mathrm{d}^{-1}$ & 56.6 & 86.4 & 33.3 & 60.9 & 1179.0 & 129.6 & 1545.8 \\
\hline
\end{tabular}

Van Huis et al. [5] shows that the most crucial factors in choosing the type of insects for dietary purposes are: life time of insects, source of nutrition, tendency to cannibalism. Two species of insects was taken into consideration: Dubia cockroach and Mealworm. Dubia cockroach in relation to mealworm is characterized by: longer lifetime duration, better source of protein, lower tendency to cannibalism [6]. Another great advantage is that they feed on the remains of inedible biomass, so it allows to close the biomass-waste cycle. The size of designed culture is $4 \mathrm{~m}^{3}$ and provides ca. $8000 \mathrm{kcal} \cdot$ day $^{-1}$ [5]. Insects are the source of $1000 \mathrm{kcal} \cdot$ crewmember $^{-1} \cdot$ day $^{-1}$. Cockroaches' daily food requirements is ca. $4 \mathrm{~kg}$. For proper evolution of insects temperature is kept around $30^{\circ} \mathrm{C}$ and humidity around $80 \%$ [5]. Another element in mission dietary conception is Cyanobacteria (species: Arthrospira platensis). Designed culture will supplement the crew demand for macro and microelements. Bacteria produce a diverse range of valuable chemicals and biologically active compounds, such as vitamins, carotenoid pigments, proteins, lipids and polysaccharides [4]. The lack of cell wall improves the absorption of vitamins and minerals in human body, what is another grate advantage. Moreover Cyanobacteria has ability to air purification and oxygen production, so 
they also will be a part of atmosphere subsystem. Moorhead et al. [4] refers $3 \mathrm{~g}$ of cyanobacteria provides required daily dose of vitamins for a crewmember.

\subsection{Cultivation module description}

Crops are cultivated in aeroponic cultivation module. This cultivation method is based on soilless system. As shown in the Figure 3 plants are located on special rack and their roots zone are fall freely in the air [7]. Due to undeniable advantages of this type of cultivation, it is recently gaining more and more attention $[8,9]$. Komosa et al. [8] refers the main benefits of aeroponic cultivation are: higher yields with optimal quality, better use of the cultivation area, increasing cultivation cycles, improvement of phytosanitary conditions, higher level of automation, production cost reduction, functioning in a closed system and widely discussed practical effects related to cooling of root systems. Aeroponic system is used in a partially closed loop. Nutrient solution is provided as a product, gained while treating wastewater. Before medium is sprinkled into plants roots it is filtered and sterilized. Water from cultivation is recovered in a form of condensate (liquid and gaseous form) and recirculated as partly used nutrient solution. Evaporation and recirculation is supported by blowers placed in the cultivation module.

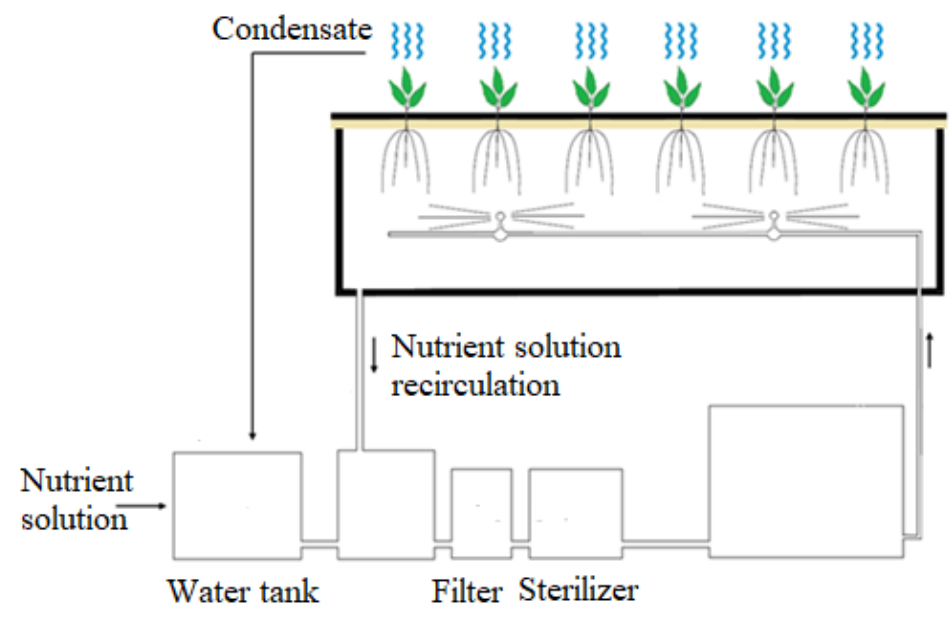

Fig. 1. Aeroponic system scheme [7].

In this concept plantation is divided into two different sizes zones. Plants are located at internal side of module (as shown in the Figure 4). The total surface of the walls is $255 \mathrm{~m}^{2}$. Crops cultivation occupy $235 \mathrm{~m}^{2}$. The rest of the surface $\left(20 \mathrm{~m}^{2}\right)$ is intended for communications. Smaller zone is dedicated to Strawberry, Tomato and Snap Bean growth. It was selected with respect to similar growth cycle. Thus, exchange of plants is facilitated. In the bigger module Soybean, Wheat and White Potato are grown.

Aeroponic module and detailed aeroponic infrastructure is shown in Figure 4. Seeds are located between two layers - plastic film and mineral wool. The hole in the film layer is used to place in there grain. On the inside is covered with mineral wool. Module design is inspired by DLR (German Aerospace Center) project [10]. Seed layer is placed on the rack. On the bottom of the module is located nutrient solution delivery pipeline and atomizer, which allows to sprinkle the medium to the roots zone. Whole module is created from interconnected modules. 


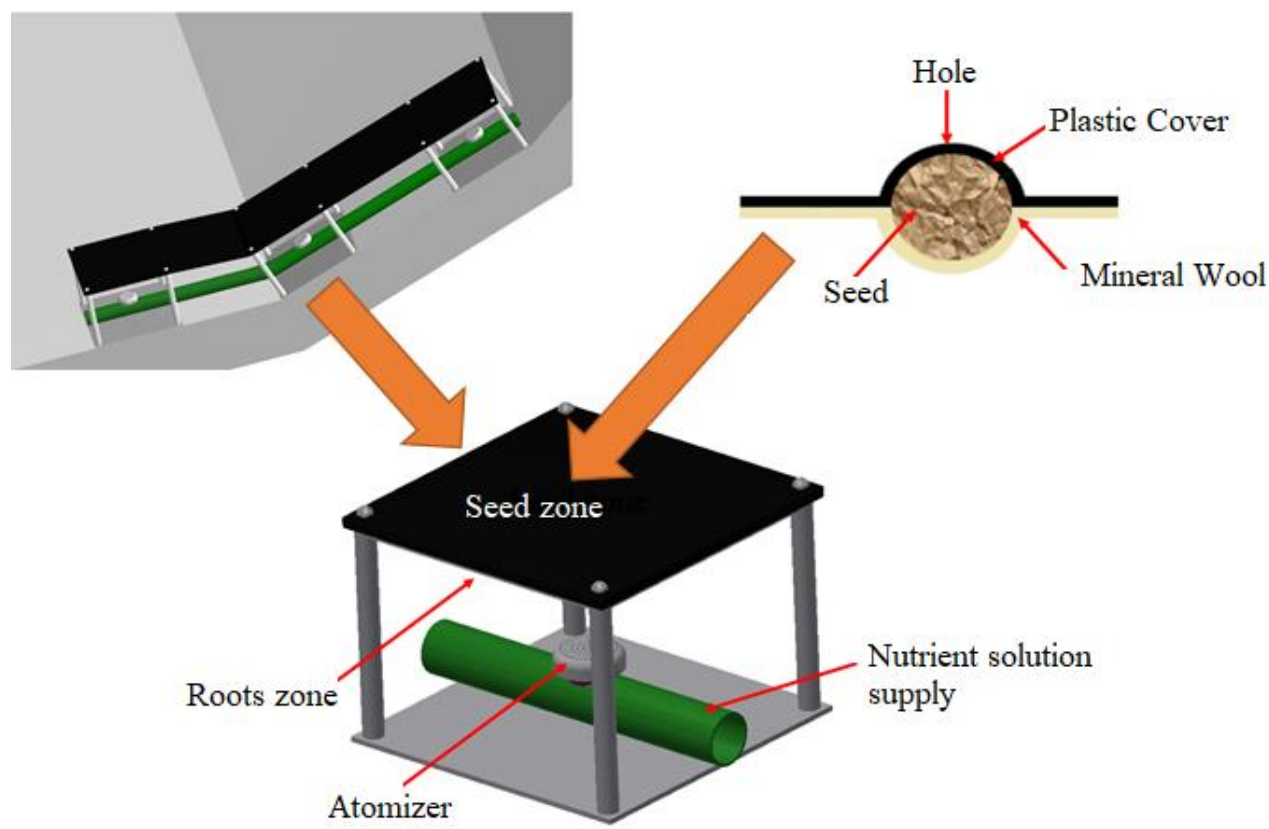

Fig. 2. Aeroponic cultivation module scheme.

Essential issues in plants cultivation are: lightning and carbon dioxide demand, which are one of the main factor for plants efficient grow [11]. First parameter, illumination is provided by system designed as VEGGIE system used on the ISS [11]. Aeroponic module is illuminated for $16 \mathrm{~h}$ by different LED lamps, characterized by high efficiency ( $40 \%$ at maximum light ) [3]. For Snap Bean, Soybean, Strawberry, Tomato, White potato, LED is used with light intensity more than $300 \mu \mathrm{mol} \cdot \mathrm{m}^{-2} \cdot \mathrm{s}^{-1}$, which is optimum rate [12]. LED lamps with light intensity $1500 \mu \mathrm{mol} \cdot \mathrm{m}^{-2} \cdot \mathrm{s}^{-1}$ ) are used in Wheat cultivation. Lastly in Cyanobacteria culture lamp with light intensity of $3000 \mu \mathrm{mol} \cdot \mathrm{m}^{-2} \cdot \mathrm{s}^{-1}$ is used [13]. Latter parameter, carbon dioxide demand is higher than astronaut production capacity. However, the remaining amount of carbon dioxide might be supplemented from other sources e.g. from wastewater treatment system, where nitrification process and oxidation of organic compounds is conducted, in which byproduct is carbon dioxide.

\section{Water subsystem}

\subsection{Wastewater generated in extraterrestrial colony}

Wastewater generated in the colony are as follows: blackwater (urine and feces), grey water (laundry, dish washing, hygiene water, remained water after the preparation of meals etc.) and a condensate (sweat, tears, water captured by the ventilation system). The last one is especially seen in microgravity condition, but in lower gravity condition also might be seen [3]. In this concept only liquid wastewater are taken into consideration. Thus, streams inflowing to the wastewater treatment unit are as follows: urine, grey water and condensate. Urine is widely known as potential fertilizer, due to high nitrogen and phosphorus content $[14,15]$. Grey water are partly treated and partly used as the diluting agent. Dilution might be required as bioreactor effluent is more concentrated than required plant intake (e.g. 
required $\mathrm{N}^{-\mathrm{NO}_{3}}$ concentration in nutrient solution for tomato aeroponic cultivation is $0.21 \mathrm{~g} \cdot \mathrm{L}^{-1}[8]$ and exemplary effluent concentration is $1.18 \mathrm{~g} \cdot \mathrm{L}^{-1}$, so it has to be diluted).

\subsection{Wastewater treatment system description}

Wastewater treatment system conception is shown in Figure 5. Main components of the system are nitrification bioreactor equipped with bubble-free aeration module and magnetic separator.

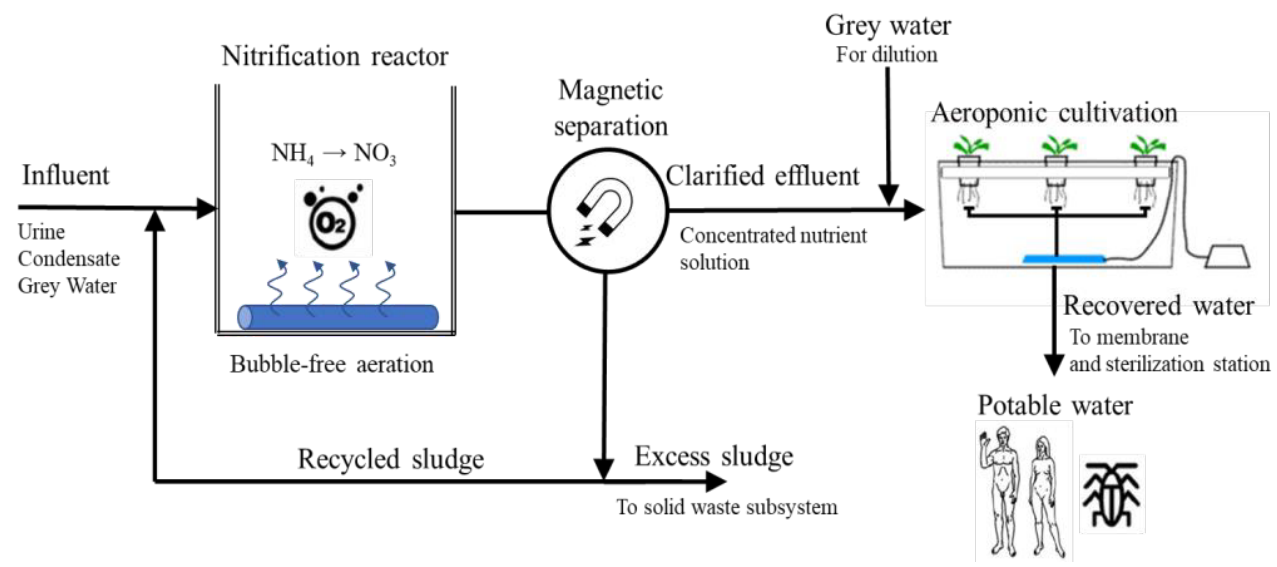

Fig. 3. Wastewater treatment system scheme.

Nitrate is a main element required in aeroponic nutrient solution regardless of the type of plant $[7-9,16]$. Hence, the system is based on an aerobic biological reactor in which the nitrification process is carried out, where ammonia or ammonium is oxidized and end product is nitrate [17]. To counteract the impact of reduced gravity on the aeration system, the bubblefree aeration is used. This solution based on diffusion interactions is popular in terrestrial condition and it might be well implemented in space systems [18]. Another issue in space biological wastewater treatment system is separation and recirculation of recycled sludge, which might be impeded due to decreased or lack of sedimentation (lack or lower gravity). For this purpose activated sludge is supplemented with magnetite (ferromagnetic powder) [19]. Separation is conducted in magnetic separator, where sludge is captured by magnetic forces. Excess sludge is returned to the reactor, and purified wastewater is transported to the aeroponic cultivation. As mentioned before, depending on the type of cultivated plant it might be necessary to dilute the nutrient solution stream. Further, water from aeroponic cultivation is recovered. It might be necessary to treat recovered water with physicochemical methods (e.g. membrane technique) and to sterilize it. However, water collected from plants transpiration is said to be extremely clean, without any need to purify it again [20].

\section{Scientific and technical challenges}

Development of efficient Life Support System is extensively researched since first manned flight. Many different technologies were tested, but still ideal solution has not been found. This concept's proposal is to recover water after it is used by plants. This approach allows to firstly recover nutrients for cultivation, and further recover water. However, there are still many and an extensive research is needed either for aeroponic cultivation system and wastewater treatment system. Although aeroponic cultivation is widely investigated in 
terrestrial conditions [7-9], no research has been conducted in microgravity conditions to the author's best knowledge. Study on exact behavior of water drops in aeroponic system in lower or microgravity condition should be conducted. The results of such an experiment could determine, if aeroponic cultivation is a feasible solution with respect to extraterrestrial conditions. Another problem with this type of biomass system could be related to lack or excess of nutrients. They will be recovered from wastewater generated in the colony, whose generation rates and composition can vary strongly. In fact, this is another issue. Wastewater streams has not been investigated precisely in regard to their generation rates and composition. While microgravity affects the human body, it also has an impact on the composition of metabolic waste (urine, feces, sweat) $[2,3,20]$. In closed loop system these waste streams are going to be a main source of nutrient and water, therefore wastewater system efficiency is the greatest importance. It leads to another issue, which is finding more suitable solution for wastewater treatment in future extraterrestrial colony than psychochemical methods currently used. While it is a feasible application in short duration missions and short distances in long-term missions there is a need to build a system, which parts can be produced on site. It is in the case of biological method of wastewater treatment. Bioreactor parts could be printed with use of a 3D printer. Moreover, it is a more beneficial solution because it could provide simultaneous recovery of water and nutrient solution for cultivation. However, some questions are still unanswered. The exact efficiency of magnetic separation and bubble-free in activated sludge reactor should be determine regarding lower gravity conditions. Understanding the essence of the problems and firstly beginning with basic step, which is determination of wastewater streams characteristic might be a milestone in designing LSS.

\section{References}

1. W.A. Jackson, A. Morse, N. Landes, D. Low, An optimum biological reactor configuration for water recycling in space, SAE Technical Paper 2009-01-2564 (2009)

2. S. Xia, A. Morse, A. Jackson, T.F. Wiesner, Simulation of a closed loop wastewater treatment system for extended space flight, Industrial Electronics and Applications, 2008. ICIEA 2008. $3^{\text {rd }}$ IEEE Conference (2008)

3. M.S. Anderson, M.K. Ewert, J.F. Keener, S.A. Wagner, Life Support Baseline Values and Assumptions Document. National Aeronautics and Space Administration Washington, D.C. Report No. NASA/TP-2015-218570 (2015)

4. K. Moorhead, B. Capelli, G. Cysewski, Spirulina Nature's Superfood, version 5 ISBN:0-9637511-3-1 (2011)

5. A. Van Huis, J. Van Itterbeeck, H. Klunder, E. Mertens, A. Halloran, G. Muir, P. Vantomme, Edible insects: future prospects for food and feed security, FAO Forestry Paper 171. FAO, Rome, Italy (2013)

6. J. Erens, S. Es Van, F. Haverkort, E. Kapsomenou, A. Luijben, A bug's life. Project 1052: Largescale insect rearing in relation to animal welfare (2012)

7. A. Komosa, Aeroponiczna uprawa roślin ogrodniczych, X Ogólnopolskie Sympozjum Naukowe Efektywność stosowania nawozów w uprawach ogrodniczych, Kraków, 17-18 czerwca 2004 (2004)

8. A. Komosa, T. Kleiber, B. Markiewicz, Acta Scientiarum Polonorum 13, 163-177 (2014)

9. C.B. Christie, M.A. Nichols, Aeroponics - A production system and research tool, In South Pacific Soilless Culture Conference-SPSCC 648, 185-190 (2003)

10. C. Zeidler, V. Vrakking, M. Bamsey, L. Poulet, P. Zabel, D. Schuber, C. Paill, 
E. Mazzolen, N. Domurath, Open Agriculture 2, 116-132 (2017)

11. G. Boscheri, C. Lobascio, M.M. Lamantea, I. Locantore, V. Guarnieri, D. Schubert, The EDEN ISS Rack-Like Plant Growth Facility, 46 ${ }^{\text {th }}$ International Conference on Environmental Systems (2016)

12. P. Zabel, M. Bamsey, D. Schubert, M. Tajmar, Life Science in Space Research 10, 1-16 (2016)

13. C. Wang, C. Fub, Y. Liu, Biochemical Engineering Journal 37, 21-25 (2007)

14. T. Karak, P. Bhattacharyya, Resources, Conservation and Recycling, 55, 4, 400-408 (2011)

15. H. Heinonen-Tanski, A. Sjöblom, H. Fabritius, P. Karinen, Bioresource Technology 98, 214-217 (2007)

16. I. Farran, A.I.M. Mingo-Castel, Amer. J. of Potato Res. 83, 47-53 (2006)

17. E. Metcalf, M. Eddy, Wastewater engineering: treatment and Resource recovery (Mic Graw-Hill, USA, 2014)

18. R. Sevanthi, D. Christenson, A. Morse, WA. Jackson, C. Meyer, L. Vega, Impact of waste stream composition and loading regime on the performance of a new flight compatible membrane-aerated biological reactor, 46th International Conference on Environmental Systems, 10-14 July 2016, Vienna, Austria (2016)

19. S.D. Archer, G.D. Hitchens, H.S. Jabs, A.K. Campbell, M.A. Edeen, A high efficiency magnetic activated sludge reactor for wastewater processing, SAE Technical Paper No. 1999-01-1945 (1999)

20. A. Begeer, A. Jackson, A. Morse, Biologically treated wastewater for NFT plant production in space, SAE Technical Paper No. 2003-01-2681 (2003) 